\title{
Synthesis of a Green Nano-Silica Material Using Beneficiated Waste Dunites and Its Application in Concrete
}

\author{
A. Lazaro ${ }^{1}$, G. Quercia ${ }^{1,2}$, H. J. H. Brouwers ${ }^{1}$, J. W. Geus ${ }^{3}$ \\ ${ }^{1}$ Department of the Built Environment, Eindhoven University of Technology, Eindhoven, The Netherlands \\ ${ }^{2}$ Materials innovation institute (M2i), Delft, The Netherlands \\ ${ }^{3}$ Debye Institute for Nanomaterials Science, University of Utrecht, Utrecht, The Netherlands \\ Email: a.lazaro.garcia@tue.nl,g.quercia@tue.nl,jos.brouwers@tue.nl,j.w.geus@uu.nl
}

Received June 23, 2013; revised July 24, 2013; accepted July 31, 2013

Copyright (C) 2013 A. Lazaro et al. This is an open access article distributed under the Creative Commons Attribution License, which permits unrestricted use, distribution, and reproduction in any medium, provided the original work is properly cited.

\begin{abstract}
Nano-silica, one of the substances boosting the field of nanomaterials, can be produced by dissolving olivine in acid. The dissolution of olivine is a convenient alternative route to the existing methods of nano-silica production (neutralization of sodium silicate and flame hydrolysis) because the olivine dissolution is a low temperature process making this method cheaper and greener. Furthermore, this process can use waste olivine materials for the production of nano-silica. The produced nano-silica has a specific surface area between 100 and $400 \mathrm{~m}^{2} / \mathrm{g}$; a primary particle size between 10 and $25 \mathrm{~nm}$, which is agglomerated in clusters; and an impurity content below $5 \mathrm{wt} . \%$. In addition, olivine nano-silica can be classified as a pozzolanic material with an activity index of $101 \%$. The optimum replacement level of olivine nano-silica in conventional vibrated concrete is around $5 \%$ by volume resulting in: 1) a compressive strength increase of $20 \%$; $)$ a $\mathrm{CO}_{2}$ emission reduction of 3\%. Therefore, the use of the olivine nano-silica in CVC does not only improve the compressive strength but also reduce the $\mathrm{CO}_{2}$ emissions.
\end{abstract}

Keywords: Olivine; Nano-Silica; $\mathrm{CO}_{2}$ Reduction; Environmentally Friendly; Concrete

\section{Introduction}

\subsection{Current Production of Nano-Silica}

At present, a wide range of silica products (see Figure 1) are manufactured industrially for a diverse array of applications. Silicas are mainly used for reinforcing, thickening and flattening purposes. World demand for specialty silicas, which include precipitated silica, fumed silica, silica gel and silica sol, will rise 6.3 percent per year to 2.7 million metric tons in 2014 [1].

There are two main routes for the productions of synthetic amorphous silica: the thermal route and the wet route [2]. In the thermal route, also called flame hydrolysis, highly dispersed silicas are formed from the gas phase at high temperatures. Silicon tetrachloride, which is the usual raw material, is continuously vaporized, mixed with dry air, then, with hydrogen and finally fed to a burner where it is hydrolyzed in an oxygen-hydrogen flame. The flame temperature depends on the properties of the burner and the desired characteristics of nano-silica. Moore patented a cooled plug burner to produce py-

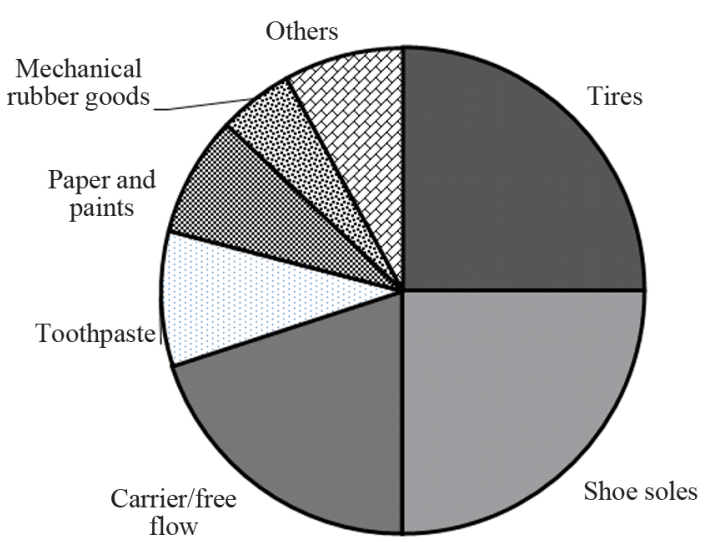

Figure 1. Worldwide consumption and use of precipitated silica in 1999 [5].

rogenic silica in a temperature range between $1000^{\circ} \mathrm{C}$ and $1200^{\circ} \mathrm{C}$ [3]. In the wet route or sol-gel process, a waterglass solution is mixed with acid (e.g. sulfuric acid) releasing the silica. Waterglass is produced by melting quartz sand with soda from temperatures of $1000^{\circ} \mathrm{C}$ to 
$1300^{\circ} \mathrm{C}[4]$; subsequently, the resulting solid waterglass is hydrothermally dissolved in water. Apart from silica produced by these processes, we also have to take into account the silica fume because it is the main silica used in cement materials. Silica fume is a byproduct of the reduction of quartz for the production of silicon and ferrosilicon. It is a very fine powder consisting of noncrystalline silica spheres with an average diameter of ca. $0.1 \mu \mathrm{m}$, and it is produced at temperatures of about $2000^{\circ} \mathrm{C}[6,7]$.

In the above production methods, a high-temperature process is involved. To reach these temperatures, huge amounts of fuel are consumed making these processes: a) unsustainable because of the scarcity of fuels; b) environmental unfriendly because of the huge amount of $\mathrm{CO}_{2}$ emitted; and c) expensive because of the fuel price.

This paper is structured in two parts: first, the production of olivine nano-silica using beneficiated waste dunite; and second, the application of olivine nano-silica in concrete. Here, we demonstrate that the dissolution of olivine is an optimal method to produce an amorphous nano-silica. This method is greener and cheaper than the conventional production methods because the reaction temperature is between $50^{\circ} \mathrm{C}$ and $95^{\circ} \mathrm{C}$. The reaction is exothermic [8], and because of waste dunites, after beneficiation, it can be used as a silica source. The use of nano-silica in conventional vibrated concrete can reduce the $\mathrm{CO}_{2}$ emissions by $3 \%$ and increase the compressive strength by $20 \%$.

\subsection{Application of Nano-Silica in Concrete}

Concrete is the most widely used construction material and consists of water, aggregates and cement. World production of cement increased up to 3.6 billion tons in 2011 [9]. Nano-silica in concrete is not yet commonly applied, but silica fume, which is considered a microsilica, has already been used in concrete for several years to make high-performance concrete. The use of microsilica in concrete continues to increase despite its relatively high cost because of its pozzolanic behavior and its content of fine particles. These two features of the microsilica confer some benefits to the concrete. The pozzolanic behavior refers to the reaction between silica and portlandite, $\mathrm{Ca}(\mathrm{OH})_{2}$, to produce $\mathrm{CSH}$ (calcium silicate hydrate) gel, which is the main phase contributing to the concrete's strength.

Also, because of its small particle size, micro-silica fills the voids between the cement particles; this improves the packing factor and reduces the porosity. Besides the above mentioned features, nano-silica has the following effects on cement pastes and concrete mixes: acceleration of the setting, cement matrix densification and improvement of the interparticle transition zone (ITZ) of aggregates (filling effect).
Because of the pozzolanic reaction, micro-silica can replace cement (1 part silica instead of 3 to 4 parts cement) for medium-strength concrete, while the strength is unaffected by the replacement [10]. Considering that the main difference between nano-silica and micro-silica is their particle sizes - assuming pozzolanic behaviors in each are similar-nano-silica will react faster with the cement due to its smaller particles. Therefore, the replacement of cement by nano-silica should considerably reduce the $\mathrm{CO}_{2}$ emissions of the concrete. That is important because the cement industry is one of the industrial sectors that releases large amounts of $\mathrm{CO}_{2}$ into the environment accounting for $8 \%$ of global $\mathrm{CO}_{2}$ emissions [11]. In addition to this interesting application, the largest use of micro-silica is for producing concrete with enhanced properties, such as high early strength or low permeability.

\subsection{Olivine Silica Production}

Before beginning this section, it is necessary to clarify the difference between olivine and dunite for readers unacquainted with geology terms. Olivine refers to the mineral $(\mathrm{Mg}, \mathrm{Fe})_{2} \mathrm{SiO}_{4}$ and dunite refers to a rock where $90 \%$ of the volume is made up of olivine. The remaining $10 \%$ present in dunite ores can consist of pyroxenes, amphiboles, micas, carbonates, serpentines, etc. In many weathering and dissolution studies, pure olivines were used [12-14], but in this study, and our previous work [15], dunite had been used because we focused on the commercial production of olivine nano-silica.

The dissolution of olivine in acid at low temperatures (between $50^{\circ} \mathrm{C}$ and $95^{\circ} \mathrm{C}$ ) produces amorphous silica:

$$
(\mathrm{Mg}, \mathrm{Fe})_{2} \mathrm{SiO}_{4}+4 \mathrm{H}^{+} \rightarrow \mathrm{Si}(\mathrm{OH})_{4}+2(\mathrm{Mg}, \mathrm{Fe})^{2+}
$$

The dissolution yields a slurry consisting of a mixture of magnesium/iron sulfates, amorphous silica, unreacted olivine and inert minerals. The silica can be separated from the resulting suspension by washing and filtration. A flow chart of this process is presented in Figure 2. The colloidal chemistry of silica strongly depends on the amount of salt and the $\mathrm{pH}$ of the solution. At the $\mathrm{pH}$ levels of the olivine silica process ( -0.5 to 1$)$, a colloidal solution of silica is usually unstable, and the silica particles polymerize [4].

In addition to the low temperature of this procedure (below $95^{\circ} \mathrm{C}$ ), it is remarkable that the process is exothermic with a reaction heat of $223 \mathrm{KJ}$ per mole of olivine [8]. The energy generation during the olivine nano-silica process for an adiabatic reactor is shown in Table $\mathbf{1}$. When 1.5 moles of olivine react with sulfuric acid, the temperature of the mixture will increase to $84^{\circ} \mathrm{C}$. Therefore, the reaction generates more than enough energy to keep the system at the desired temperature (between $50^{\circ} \mathrm{C}$ and $90^{\circ} \mathrm{C}$ ) provided the reactor is sufficiently large and well insulated. 


\section{Materials and Methods}

The chemical composition of different dunites analyzed by X-ray fluorescence (XRF) is shown in Table 2. The first three dunites were from Norway, and the others were from Greece. The Greek dunites were a waste material generated from the magnesite mining activities in Gerakini. The loss of ignition (LOI) of GR-PROMGM-1 and GR-PROMGM-3 is too high, which is presumably related to the presence of serpentine and carbonate minerals, but not to olivine. These waste rocks were beneficiated by dense media separation, resulting in samples GR-PROMGM- $4,-8$ and -10 , with a LOI below $2.5 \%$. The olivine content of these samples was determined by X-Ray diffraction (XRD), XRF and thermogravimetric (TG) techniques. The olivine content was about $89 \%$ for the Norwegian dunites whereas in the Greek dunites it

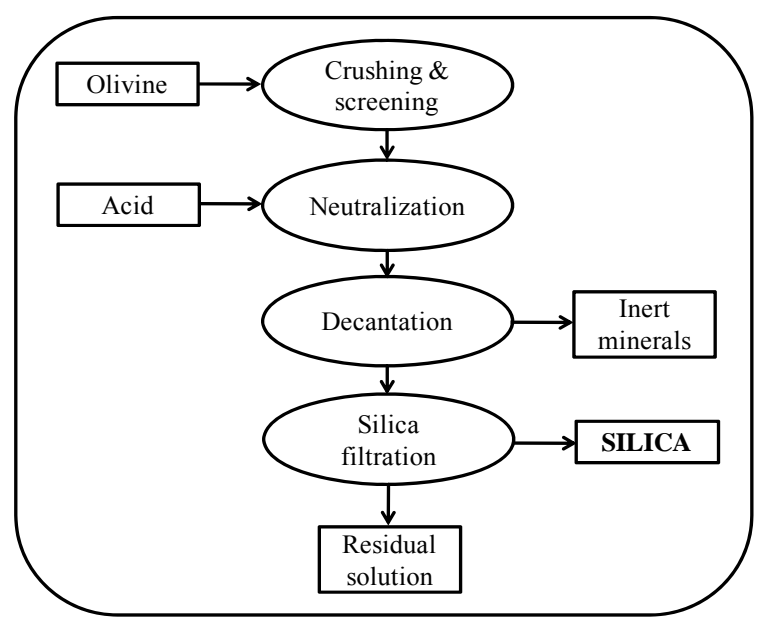

Figure 2. Flow chart of the olivine process.

Table 1. Energy generation during the olivine nano-silica process.

\begin{tabular}{ccccccc}
\hline $\begin{array}{c}\mathrm{H}_{\mathrm{r}} \\
(\mathrm{kJ} / \mathrm{mol})\end{array}$ & $\begin{array}{c}\mathrm{n}_{\mathrm{ol}} \\
(\mathrm{mol})\end{array}$ & $\begin{array}{c}\mathrm{V}_{\mathrm{H}_{2} \mathrm{O}_{4}} \\
(\mathrm{l})\end{array}$ & $\begin{array}{c}{\left[\mathrm{H}_{2} \mathrm{SO}_{4}\right]} \\
\mathrm{mol} / 1\end{array}$ & $\mathrm{X}$ & $\begin{array}{c}\mathrm{Q} \\
(\mathrm{kJ})\end{array}$ & $\begin{array}{c}\mathrm{T} \\
\left({ }^{\circ} \mathrm{C}\right)\end{array}$ \\
\hline 223 & 1.5 & 1 & 3 & 100 & 333.5 & 84 \\
\hline
\end{tabular}

was lower (see Table 2). The samples after beneficiation, PROMGM-4, -8 and -10 , doubled the olivine content of the original non beneficiated waste material.

Nano-silica production experiments were carried out at $50^{\circ} \mathrm{C}, 70^{\circ} \mathrm{C}$ and $90^{\circ} \mathrm{C}$ with olivine particles of $125-150$, $250-300$ and $500-600 \mu \mathrm{m}$ in a stirred, thermostated reactor of one liter. The reagents used were $500 \mathrm{ml}$ of 3 $\mathrm{M}$ sulfuric acid and the stoichiometric amount of olivine, previously dried. The neutralization reaction continued until the $\left[\mathrm{H}^{+}\right]$was below $0.1 \mathrm{~mol} / 1$ when it was stopped. Then the suspension was separated from the solid residue by sedimentation. Subsequently, the remaining slurry was washed and filtered to obtain the clean amorphous nanosilica (more details can be found in [15]).

The nano-silica produced was characterized by nitrogen physisorption, transmission electron microscopy (TEM), X-ray fluorescence (XRF), and combustion infrared analysis (determination of sulfur content). A Micromeritics TriStar 3000 equipment using $\mathrm{N}_{2}$ with a soaking time of $240 \mathrm{~min}$ above $100^{\circ} \mathrm{C}$ was used for the gas physisorption analysis [16] in order to remove the physisorbed water. The physisorbed water is completely removed from the silica at $200^{\circ} \mathrm{C}$, but all the silanol groups still remain [17]. The presence of remaining water decreases the adsorption of nitrogen on the surface of the solid material. The difference in the $\mathrm{SSA}_{\mathrm{BET}}$ between an olivine nano-silica with a soaking temperature of $120^{\circ} \mathrm{C}$ and $190^{\circ} \mathrm{C}$ was around $20 \%$ for an olivine nano-silica of $345 \mathrm{~m}^{2} / \mathrm{g}$ with a soaking temperature of $190^{\circ} \mathrm{C}$. In this study two soaking temperatures for olivine nano-silica are used in order to compare the results of Greek dunite with Norwegian dunite, which were analyzed at $120^{\circ} \mathrm{C}$ in our previous study [15]. The specific surface area, $\mathrm{SSA}_{\mathrm{BET}}$, was calculated using the BET $[16,18]$. The specific external surface area, $\mathrm{SSA}_{\mathrm{E}}$, and the specific micropore surface area, $\mathrm{SSA}_{\mathrm{MP}}$, were calculated using the t-plot method [19,20] from the slope of the t-plot curve [21]. The particle size of the nano-silica was calculated from the geometrical relationship between surface area and mass given by

Table 2. Chemical composition of the different dunites.

\begin{tabular}{|c|c|c|c|c|c|c|c|c|c|c|c|c|}
\hline Dunite & MgO & $\mathrm{Fe}_{2} \mathrm{O}_{3}$ & $\mathrm{SiO}_{2}$ & $\mathrm{Cr}_{2} \mathrm{O}_{3}$ & $\mathrm{Al}_{2} \mathbf{O}_{3}$ & NiO & MnO & $\mathrm{CaO}$ & $\mathrm{Na}_{2} \mathrm{O}$ & LOI & $\begin{array}{l}\text { Other } \\
\text { Oxides }\end{array}$ & Olivine \\
\hline NO-CRS-1 & 47.41 & 7.84 & 41.42 & 0.31 & 0.75 & 0.33 & 0.12 & 0.34 & 0.06 & 1.29 & 0.13 & 88.4 \\
\hline GL50 & 49.32 & 7.32 & 41.44 & 0.31 & 0.46 & 0.32 & 0.09 & 0.15 & 0.02 & 0.59 & 0.00 & 88.9 \\
\hline GR-PROMGM-1 & 41.62 & 8.63 & 41.46 & 0.5 & 0.52 & 0.3 & 0.15 & 0.69 & 0.09 & 5.92 & 0.12 & 44.0 \\
\hline GR-PROMGM-3 & 34.47 & 7.95 & 43.51 & 0.45 & 1.78 & 0.25 & 0.14 & 1.33 & 0.33 & 9.6 & 0.19 & 29.0 \\
\hline GR-PROMGM-4 & 43.93 & 9.01 & 43.60 & 0.44 & 0.56 & 0.32 & 0.13 & 0.70 & 0.00 & 1.33 & 0.00 & 75.0 \\
\hline GR-PROMGM-8 & 43.79 & 8.90 & 42.67 & 0.41 & 0.59 & 0.31 & 0.13 & 0.65 & 0.00 & 2.55 & 0.00 & 75.0 \\
\hline GR-PROMGM-10 & 45.12 & 8.79 & 41.92 & 0.42 & 0.54 & 0.31 & 0.12 & 0.83 & 0.00 & 1.95 & 0.00 & 75.0 \\
\hline
\end{tabular}




$$
d(\mathrm{~nm})=\frac{6000}{S S A_{B E T} \cdot \rho}
$$

where $d$ is the particle size of nano-silica considered to be spherical $(\mathrm{nm}), \rho$ the density of the material, 2.2 $\left(\mathrm{g} / \mathrm{cm}^{3}\right)$ for nano-silica, and SSA the surface area $\left(\mathrm{m}^{2} / \mathrm{g}\right)$. This particle size is an average value considering that the particles are spherical.

\section{Results}

\subsection{Olivine Nano-Silica from Norwegian Dunite}

The experiments performed with Norwegian dunite are presented in Table 3 together with the amount of reagents, the molecular ratio of hydrogen ion versus olivine, the average particle size of olivine $\left(\mathrm{d}_{\mathrm{OL}}\right)$ and the reaction temperature. The values of the specific surface area, pore size and particle size of olivine nano-silica (equation (1)) are collected in Table 4. Figure 3 shows a TEM picture of sample NS-7 [15]. The chemical composition of the nano-silica produced in these experiments is shown in Table 5. The total sulfate, the sulfate limit for the appli-

Table 3. Initial conditions of the nano-silica production experiments.

\begin{tabular}{cccccc}
\hline Title & $\begin{array}{c}\mathrm{m}_{\mathrm{H}_{2} \mathrm{SO}_{4}} \\
(\mathrm{~g})\end{array}$ & $\begin{array}{c}\mathrm{m}_{\mathrm{ol}} \\
(\mathrm{g})\end{array}$ & $\begin{array}{c}\text { Ratio } \\
\mathrm{H}^{+} / \mathrm{Ol}\end{array}$ & $\begin{array}{c}\mathrm{d}_{\mathrm{ol}} \\
(\mu \mathrm{m})\end{array}$ & $\begin{array}{c}\mathrm{T}_{\text {reactor }} \\
\left({ }^{\circ} \mathrm{C}\right)\end{array}$ \\
\hline $\mathrm{NS}-1$ & 589.1 & 109.8 & 4.5 & 138 & 48.7 \\
$\mathrm{NS}-2$ & 593.5 & 125.0 & 4.0 & 200 & 52.0 \\
$\mathrm{NS}-3$ & 555.8 & 121.7 & 3.8 & 400 & 55.0 \\
$\mathrm{NS}-4$ & 532.7 & 112.6 & 4.0 & 313 & 70.2 \\
$\mathrm{NS}-5$ & 593.9 & 122.9 & 4.0 & 400 & 70.7 \\
$\mathrm{NS}-6$ & 594.2 & 113.1 & 4.4 & 550 & 69.9 \\
$\mathrm{NS}-7$ & 593.7 & 119.4 & 4.2 & 275 & 87.7 \\
$\mathrm{NS}-8$ & 592.3 & 121.5 & 4.1 & 400 & 86.2 \\
\hline
\end{tabular}

Table 4. Properties of olivine nano-silica produced using Norwegian olivine.

\begin{tabular}{ccccccc}
\hline Title & $\begin{array}{c}\mathrm{SSA}_{\mathrm{BET}} \\
\left(\mathrm{m}^{2} / \mathrm{g}\right)\end{array}$ & $\begin{array}{c}\mathrm{SSA}_{\mathrm{MP}} \\
\left(\mathrm{m}^{2} / \mathrm{g}\right)\end{array}$ & $\begin{array}{c}\mathrm{SSA}_{\mathrm{E}} \\
\left(\mathrm{m}^{2} / \mathrm{g}\right)\end{array}$ & $\begin{array}{c}\mathrm{d}_{\mathrm{p}_{2} \mathrm{~A}} \\
(\mathrm{~nm})\end{array}$ & $\begin{array}{c}\mathrm{d}_{\mathrm{p} \_\mathrm{D}} \\
(\mathrm{nm})\end{array}$ & $\begin{array}{c}\mathrm{d}_{\mathrm{BET}} \\
(\mathrm{nm})\end{array}$ \\
\hline NS-1 & 131 & 27 & 104 & 21 & 21 & 26 \\
NS-2 & 150 & 27 & 123 & 18 & 17 & 22 \\
NS-3 & 165 & 43 & 122 & 18 & 18 & 22 \\
NS-4 & 218 & 52 & 166 & 18 & 17 & 16 \\
NS-5 & 198 & 58 & 139 & 19 & 19 & 20 \\
NS-6 & 179 & 47 & 132 & 28 & 24 & 21 \\
NS-7 & 266 & 72 & 194 & 25 & 22 & 14 \\
NS-8 & 185 & 36 & 149 & 18 & 17 & 18 \\
\hline
\end{tabular}

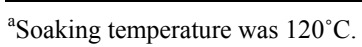

cation of silica in concrete "norm NEN - EN 13263-1 + A1" and the number of filtration steps of the olivine nano-silica are shown in Figure 4. The maximum sulfate content $\left(\mathrm{SO}_{4}\right)$ from the norm is $2.4 \%$ or $0.8 \%$ expressed as sulfur content.

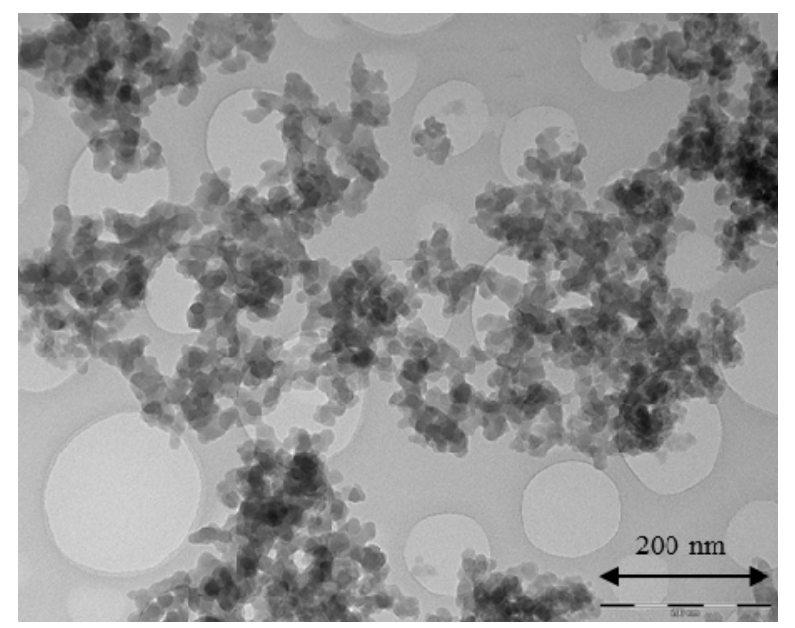

Figure 3. TEM picture (89 kx) of the olivine nano-silica NS7 [15].

Table 5. Chemical analysis of olivine nano-silica produced using Norwegian olivine.

\begin{tabular}{cccccccc}
\hline Title & $\begin{array}{c}\mathbf{S} \\
\mathbf{( \% )}\end{array}$ & $\begin{array}{c}\mathbf{M g} \\
\mathbf{( \% )}\end{array}$ & $\begin{array}{c}\mathbf{A l} \\
\mathbf{( \% )}\end{array}$ & $\begin{array}{c}\mathbf{C a} \\
\mathbf{( \% )}\end{array}$ & $\begin{array}{c}\mathbf{F e} \\
\mathbf{( \% )}\end{array}$ & $\begin{array}{c}\mathbf{N i} \\
\mathbf{( \% )}\end{array}$ & $\begin{array}{c}\mathbf{P}_{\mathbf{S i}} \\
\mathbf{( \% )}\end{array}$ \\
\hline NS-1 & 3.89 & 1.88 & 0.02 & 0.05 & 0.36 & 0.02 & 86.01 \\
NS-2 & 1.18 & 0.18 & 0.01 & 0.03 & 0.04 & 0.00 & 96.20 \\
NS-3 & 1.26 & 0.29 & 0.02 & 0.08 & 0.06 & 0.00 & 95.76 \\
NS-4 & 1.17 & 0.16 & 0.01 & 0.03 & 0.03 & 0.00 & 96.26 \\
NS-5 & 1.19 & 0.26 & 0.02 & 0.04 & 0.05 & 0.00 & 96.06 \\
NS-6 & 0.92 & 0.39 & 0.04 & 0.05 & 0.05 & 0.00 & 96.68 \\
NS-7 & 1.36 & 0.28 & 0.02 & 0.04 & 0.06 & 0.00 & 95.52 \\
NS-8 & 2.16 & 0.96 & 0.03 & 0.03 & 0.15 & 0.01 & 92.34 \\
\hline
\end{tabular}

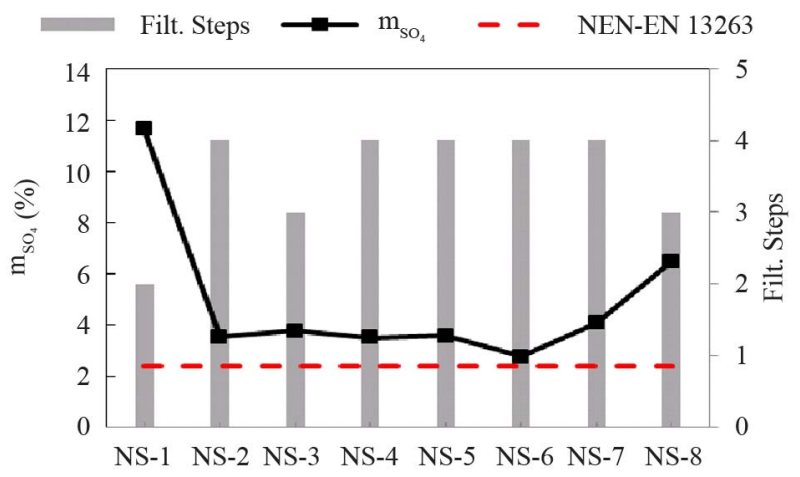

Figure 4. Sulfate content in olivine nano-silicas, sulfate limited by the norm and filtration steps. 
The silica produced in these batches contained higher amounts of sulfate than permissible in the application of silica in concrete. The sulfur content can be decreased by adding extra washing steps $[22,23]$. In the additional cleaning steps, the rinsing liquid should be distilled water instead of $\mathrm{H}_{2} \mathrm{SO}_{4} 0.1 \mathrm{M}$ in order to achieve a more effective removal of the sulfur. Purities above $99 \%$ were obtained with 6 filtration steps [22].

\subsection{Olivine Nano-Silica Using Greek Dunite}

In addition to the experiments carried out with Norwegian dunite, which were performed to validate the production of nano-silica by the olivine route, experiments with waste Greek dunite were conducted as well. PROMGM-1, $-3,-4,-8$ and -10 were tested at $90^{\circ} \mathrm{C}$ using the procedure previously described.

Although the dunite PROMGM-1 and PROMGM-3 reacted with sulfuric acid, the following problems were encountered in the treatment of the reaction mixture: a) the amount of silica produced was too low to make this process economically feasible; b) carbonates present in the Greek dunite consumed part of the hydrogen ions without producing silica; c) the violent reaction of the carbonates made control of the reactor temperature at the beginning of the experiment difficult; and d) the separation of the silica from the slurry was too difficult. The filtration issues, which is one of the major problem of this process, was due to the presence of talc and precipitate gypsum $\left(\mathrm{CaSO}_{4} \cdot 2 \mathrm{H}_{2} \mathrm{O}\right)$ in the slurry, which were likely to be formed because of the high content of $\mathrm{CaO}$ in the Greek dunites. Therefore, we conclude that PROM GM-1 and PROMGM-3 are not suitable for the production of nano-silica by the dissolution of olivine; and that a dunite material with an olivine content equal or higher than $75 \mathrm{wt} . \%$ should be used for the production of nanosilica.

The beneficiated waste Greek dunite, on the other hand, gave excellent results producing a nano-silica of high purity and high specific surface area (see Tables 6 and 7). The purity of nano-silica $\left(\mathrm{P}_{\mathrm{Si}}\right)$ was calculated by subtracting impurity values from an absolute purity $(100 \%)$, considering sulfur was in the sulfate form. With beneficiated waste dunites, no problems arose when the slurry was decanted and the silica was filtered. Nanosilica from PROMGM-8 and -10 (NS-GM-8 and -10) exhibited a higher specific surface area than NS-GM-4 and nano-silica produced from Norwegian dunite. This was mainly because the silicas contain fewer impurities. It could also be due to the high reaction temperature and short aging time, thus preventing agglomeration of silica [15], as well as the higher soaking temperature $\left(190^{\circ} \mathrm{C}\right)$ compared to the previous analysis.

The only silica that fulfilled the norm about the sulfur content in concrete was NS-GM-10, while the two other
Table 6. Properties of olivine nano-silica produced using beneficiated waste dunite (NS-GM-4, -8 and -10).

\begin{tabular}{|c|c|c|c|c|c|c|}
\hline Title & $\begin{array}{c}\mathrm{SSA}_{\mathrm{BET}} \\
\left(\mathrm{m}^{2} / \mathrm{g}\right)\end{array}$ & $\begin{array}{l}\mathrm{SSA}_{\mathrm{MP}} \\
\left(\mathrm{m}^{2} / \mathrm{g}\right)\end{array}$ & $\begin{array}{l}\mathrm{SSA}_{\mathrm{E}} \\
\left(\mathrm{m}^{2} / \mathrm{g}\right)\end{array}$ & $\begin{array}{l}d_{p_{1} A} \\
(n m)\end{array}$ & $\begin{array}{c}d_{\mathrm{p} \_\mathrm{D}} \\
(\mathrm{nm})\end{array}$ & $\begin{array}{l}d_{\text {BET }} \\
(n m)\end{array}$ \\
\hline NS-GM-4 $4^{\text {a }}$ & 275.9 & 37.6 & 238.3 & 15 & 14 & 10 \\
\hline NS-GM- $8^{\mathrm{b}}$ & 390.0 & 52.0 & 338.0 & 18 & 17 & 7 \\
\hline NS-GM-10 ${ }^{\mathrm{b}}$ & 480.0 & 58.0 & 422.0 & 19 & 19 & 6 \\
\hline
\end{tabular}

${ }^{\mathrm{a}}$ Soaking temperature was $120^{\circ} \mathrm{C},{ }^{\mathrm{b}}$ Soaking temperature was $190^{\circ} \mathrm{C}$.

Table 7. Chemical analysis of olivine nano-silica produced using beneficiated waste dunite.

\begin{tabular}{cccccccc}
\hline Title & $\begin{array}{c}\mathbf{S} \\
\mathbf{( \% )}\end{array}$ & $\begin{array}{c}\mathbf{M g} \\
\mathbf{( \% )}\end{array}$ & $\begin{array}{c}\mathbf{F e} \\
\mathbf{( \% )}\end{array}$ & $\begin{array}{c}\mathbf{C a} \\
\mathbf{( \% )}\end{array}$ & $\begin{array}{c}\mathbf{A l} \\
\mathbf{( \% )}\end{array}$ & $\begin{array}{c}\mathbf{N i} \\
\mathbf{( \% )}\end{array}$ & $\begin{array}{c}\mathbf{P}_{\mathrm{Si}} \\
\mathbf{( \% )}\end{array}$ \\
\hline NS-GM-4 & 2.32 & 1.21 & 0.30 & 0.11 & 0.03 & 0.01 & 91.39 \\
NS-GM-8 & 1.61 & 0.60 & 0.15 & 0.06 & 0.02 & 0.01 & 94.33 \\
NS-GM-10 & 0.68 & 0.41 & 0.11 & 0.08 & 0.02 & 0.01 & 97.34 \\
\hline
\end{tabular}

silicas would require additional cleaning steps for the application in concrete. From these results, it can be concluded that nano-silica of high purity and high specific surface area can be obtained from beneficiated waste dunite as long as the necessary cleaning procedure is carried out.

\subsection{Characterization of Different Nano-Silica Additives for Concrete}

Six different amorphous commercial silica samples containing either micro- or nano-particles were selected to determine their physicochemical properties (more info about the characterization of silicas for concrete can be found in [24]). The samples are classified and named as follows: two colloidal nano-silicas prepared by the water glass route (samples CNS-1 and CNS-2, respectively); one nano-silica fume in powder form (PNS-3); one micro- silica in slurry form (PMS-4); and two synthetic pyrogenic silicas in powder form (PMS-5 and PMS-6). In addition, one sample prepared by the dissolution of olivine in acid (ONS) was studied for comparison. Tables 8 and 9 display the general characteristics (taken from the product data sheets) and their chemical composition (determined by XRF), respectively.

Olivine nano-silica presents a lower density than expected due to the amount of water in the sample. This water can be present as physically adsorbed water, water involved in surface silanol and internal silanol. This nano-silica has an acidic character because it was synthesized at low $\mathrm{pH}$ (below the isoelectric point of the silica). In addition, this material has a high specific surface area and a low particle size. The primary particles, 10 to 25 $\mathrm{nm}$, are agglomerated forming 3-D network clusters (see Figure 3) [15]. The agglomerates are mesoporous, and 
Table 8. Characteristics of commercial and olivine nano-sililcas.

\begin{tabular}{|c|c|c|c|c|c|c|c|}
\hline Name & CNS-1 & CNS-2 & PNS-3 & PMS-4 & PNS-5 & PNS-6 & ONS \\
\hline Type & Colloid & Colloid & Powder & Slurry & Powder & Powder & Powder \\
\hline Production route & Water glass & Water glass & Pyrolysis & Fume & Pyrolysis & Pyrolysis & $\begin{array}{c}\text { Olivine } \\
\text { dissolution }\end{array}$ \\
\hline Specific density $\left(\mathrm{g} / \mathrm{cm}^{3}\right)$ & - & - & 2.2 & 1.4 & $2.2-2.3$ & $2.2-2.3$ & $1.9-2.1$ \\
\hline Bulk density $\left(\mathrm{g} / \mathrm{cm}^{3}\right)$ & $1.05^{(*)}$ & $1.40^{(*)}$ & $0.09-0.11^{(*)}$ & $1.40^{(*)}$ & $0.09-0.11^{(*)}$ & $0.15-0.70^{(*)}$ & 0.1 \\
\hline $\mathrm{pH}$ & $9-11$ & $9-11$ & $5^{(+)}$ & $5-7$ & $5^{(+)}$ & $5-7^{(+)}$ & $3-6^{(+)}$ \\
\hline Solid content $(\%)$ & $15^{(*)}$ & $48-52^{(*)}$ & - & $48-50^{(*)}$ & - & - & - \\
\hline Viscosity (mPa.s) & $<50^{(*)}$ & $<50^{(*)}$ & - & - & - & - & - \\
\hline LOI (\%) & - & - & $0.5^{(*)}$ & $4^{(*)}$ & $0.5^{(*)}$ & $0.5^{(*)}$ & 5 \\
\hline $\operatorname{BET}\left(\mathrm{m}^{2} / \mathrm{g}\right)$ & $200-500$ & 50 & 50 & $15-35$ & 50 & 10 & $100-400$ \\
\hline $\mathrm{d}(\mu \mathrm{m})$ & - & - & $<0.4$ & - & - & - & $<0.1$ \\
\hline
\end{tabular}

$(-)$ : Not displayed by product data sheet or not applicable; $(+): 4 \% \mathrm{~m} / \mathrm{m}$ in water; $(*)$ : values taken from product data sheet.

Table 9. Chemical analysis of commercial and olivine nano-sililcas.

\begin{tabular}{|c|c|c|c|c|c|c|c|}
\hline Name & CNS-1 & CNS-2 & PNS-3 & PMS-4 & PMS-5 & PMS-6 & ONS \\
\hline $\mathrm{SiO}_{2}$ & 97.29 & 99.33 & 99.55 & 96.12 & 99.62 & 99.55 & 98.97 \\
\hline $\mathrm{Al}_{2} \mathrm{O}_{3}$ & 0.15 & 0.07 & $<0.01$ & 0.86 & 0.18 & 0.3 & 0.05 \\
\hline $\mathrm{Fe}_{2} \mathrm{O}_{3}$ & 0.03 & 0.03 & 0.34 & 0.34 & 0.05 & 0.03 & 0.28 \\
\hline $\mathrm{MnO}$ & - & - & - & 0.04 & - & - & - \\
\hline $\mathrm{MgO}$ & $<0.01$ & $<0.01$ & $<0.01$ & 0.53 & $<0.01$ & $<0.01$ & 0.31 \\
\hline $\mathrm{CaO}$ & 0.02 & 0.01 & $<0.01$ & 0.39 & 0.01 & 0.01 & 0.04 \\
\hline $\mathrm{Na}_{2} \mathrm{O}$ & 2.15 & 0.35 & $<0.01$ & 0.21 & $<0.01$ & 0.01 & $<0.01$ \\
\hline $\mathrm{K}_{2} \mathrm{O}$ & 0.27 & 0.09 & $<0.01$ & 1.05 & 0.04 & 0.01 & 0.04 \\
\hline $\mathrm{TiO}_{2}$ & 0.02 & 0.02 & 0.01 & $<0.01$ & 0.01 & $<0.01$ & 0.01 \\
\hline $\mathrm{P}_{2} \mathrm{O}_{5}$ & 0.01 & 0.01 & 0.01 & 0.07 & 0.02 & 0.01 & 0.02 \\
\hline $\mathrm{Cr}_{2} \mathrm{O}_{3}$ & 0.01 & 0.01 & 0.01 & $<0.01$ & 0.01 & 0.02 & 0.03 \\
\hline $\mathrm{SO}_{3}$ & 0.03 & 0.05 & 0.03 & 0.36 & 0.03 & 0.03 & 0.24 \\
\hline C-Total & 0.08 & 0.08 & 0.08 & 0.66 & 0.08 & 0.07 & 0.03 \\
\hline
\end{tabular}

the porosity of the agglomerates is due to the voids between the primary particles. The morphological properties of nano-silica are of crucial importance for the application in concrete because they affect the adsorption of water and the packing factor.

\subsection{Pozzolanic Activity of Olivine Nano-Silica}

To determine the pozzolanic index of the olivine nanosilica, different cement mortars were prepared and tested following guideline CEN EN 196-1 [25]. A replacement of $7 \%$, based on the weight of binder (bwob), that is cement plus nano-silica, was selected using the procedure described by Justnes [26]. In addition, two cement mortars, with and without the replacement of cement with micro-silica (PmS-4), were prepared. The superplasticizer (SP) content (see Table 10) of the mixes was adjusted to obtain a spread flow of $175 \pm 15 \mathrm{~mm}$ ensuring the desired rheological properties of the mixture. The SP used was a polycarboxilic ether (PCE) type with a solid content of $35 \%$ and density of $1.095 \mathrm{~g} / \mathrm{ml}$. Olivine nanosilica needed more than 4 times of SP than micro-silica to exhibit a similar spread flow, and still, the result of this test was $20 \mathrm{~mm}$ smaller. There are three reasons why the rheological properties of olivine nano-silica are more 
viscous than those of micro-silica. 1) Olivine nano-silica reduced the amount of free water in the mix making it

Table 10. Mix designs of mortars used to determine the pozzonlanic index.

\begin{tabular}{cccc}
\hline Materials (g) & CEM I 52.5N & ONS & PMS-4 \\
\hline CEM I 52.5N & 450 & 418.5 & 418.5 \\
Olivine nano-silica & 0 & 31.5 & 0 \\
Micro-silica & 0 & 0 & 31.5 \\
Water & 225 & 225 & 225 \\
Standard sand & 1350 & 1350 & 1350 \\
SP & 0 & 2.25 & 0.5 \\
SP (\% bwob) & 0 & 0.5 & 0.11 \\
w/c ratio & 0.5 & 0.54 & 0.54 \\
Spread flow (mm) & $180 \pm 3$ & $167 \pm 8$ & $184 \pm 7$ \\
\hline
\end{tabular}

Where ONS and PMS-4 refer to olivine nano-silica and micro-silica. unavailable for the cement. This occurred because olivine nano-silica captured a high amount of water inside its structure as a result of its high specific surface area and mesoporosity. Therefore, less water was available to provide the correct rheological properties of the mix. 2) Also, nano-silica accelerated the hydration process of cement $[27,28]$. 3) The last factor influencing the rheological properties of the mixture was the shape of nanosilica particles. The 3-D clusters of olivine nano-silica made the slurry more viscous than the spheres of microsilica.

The flexural and compressive strengths of the mixes were determined after 1,7 and 28 days. Finally, the pozzolanic activity index was calculated based on the results of the standard cement mortar. The strength development of the different mortars is shown in Figures $\mathbf{5}$ and $\mathbf{6}$. The flexural and the compressive strengths after one day were lower for the nano-silica mortar than those of the standard and micro-silica mortars. This may be due to the higher dose of SP in the nano-silica mortar. The flexural

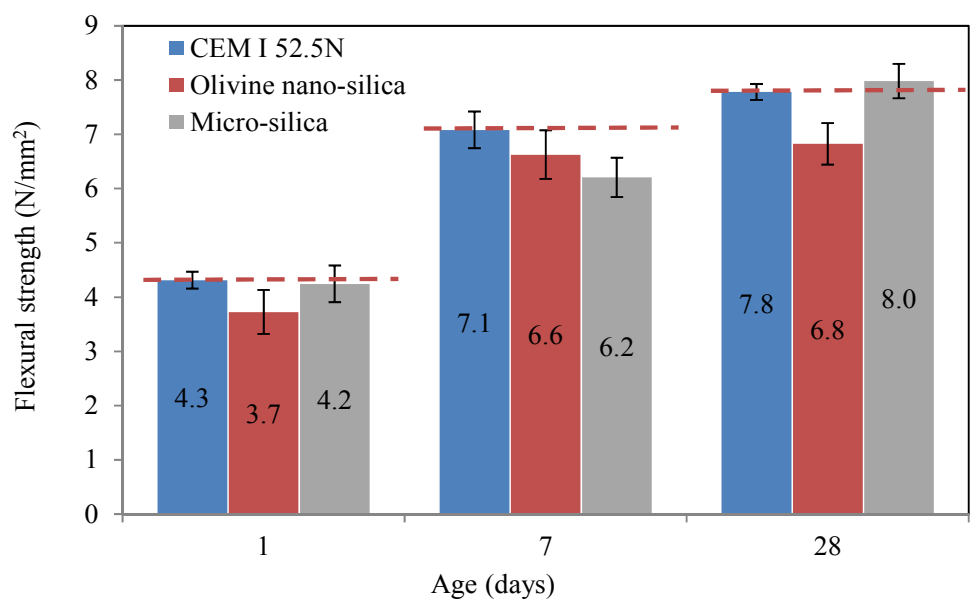

Figure 5. Flexural strength development of the tested mortars.

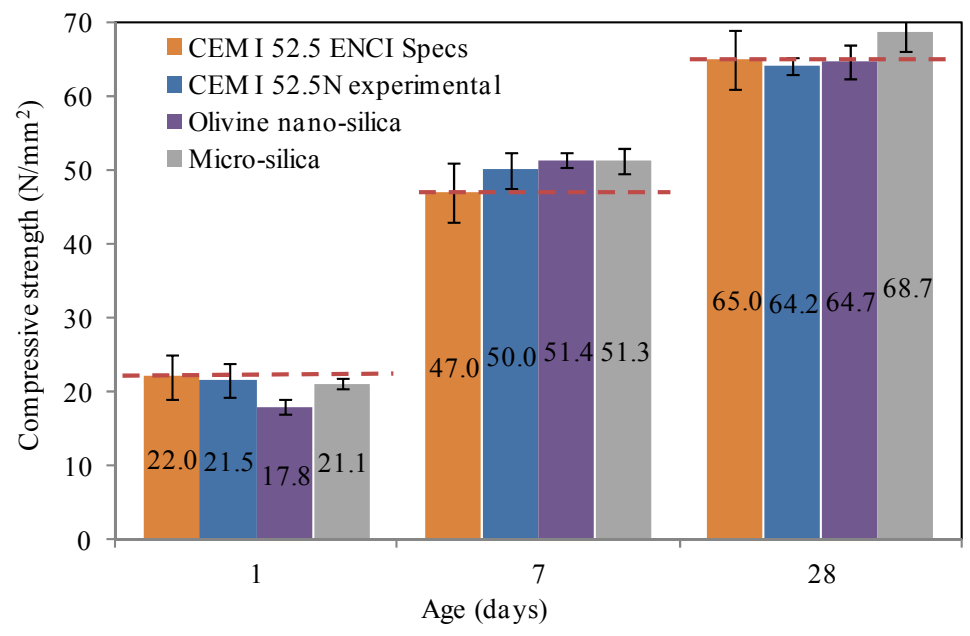

Figure 6. Compressive strength development of the tested mortars. 
strength at 28 days of the nano-silica mortar was the lowest. The compressive strength of the nano-silica mortar at 28 days showed higher values than the standard mortar, but lower than the micro-silica mortar.

The 7-day and 28-day compressive strengths were used to estimate the relative pozzolanic activity index of the olivine nano-silica and micro-silica mortars. The pozzolanic index was calculated based on the compressive strength of the reference mortar (see Figure 7).

The pozzolanic index shows that olivine nano-silica has a high pozzolanic reactivity (101\%). Therefore, olivine nano-silica can be classified as a pozzolanic material [29]. Nevertheless, the 28-day activity index was lower than the activity index of micro-silica (107\%). This was probably due to the higher specific surface area and the agglomerated state of the nano-silica, which means that the maximum wet packing was not achieved, resulting in a lower compressive strength. Despite the positive results that were obtained, further research is needed to understand the strength development of the olivine nanosilica.

\subsection{Application of Olivine Nano-Silica in Concrete}

The effect of olivine nano-silica in conventional vibrated concrete (CVC), which is the most commonly used concrete, was investigated by casting three mixes with different substitution levels of CEM I $52.5 \mathrm{~N}$ with olivine nano-silica. The mix designs were based on a commercial recipe (see Table 11); eighteen cubes were casted using a vibrating table and were tested for their slump and compressive strength after 1,7 and 28 days. The SP used was Ha-BE 100 (PCE type). Table 11 also presents the values of the slump test. The only mix with similar slump values to the reference mix was the one with $5 \%$ replacement by volume. The SP requirement for this mix was more than double compared to the reference mix. In the cases of 7 and $10 \%$ replacement, even though the SP contents were higher than the $5 \%$ replacement, it was not

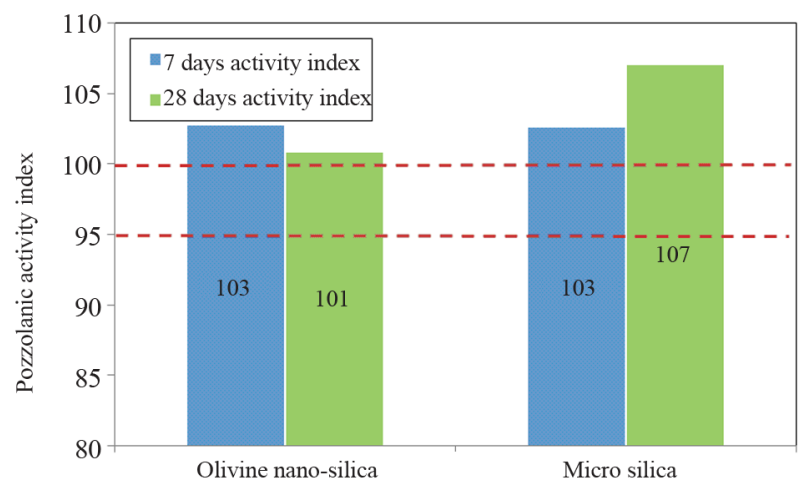

Figure 7. Pozzolanic activity index of the different mortars tested. possible to obtain the desired slump class. Therefore, when the specific surface area of the mix was raised by addition of nano-silica, more SP was required to maintain the same slump class. This is a clear disadvantage of the use of nano-silica, and it needs to be addressed in the future in order to find the type of SP that works efficiently with olivine nano-silica. Another possible solution for this problem could be to tailor the properties of olivine nano-silica to get lower specific surface areas and more spherical particles.

The compressive strengths after 1, 7 and 28 days of the $\mathrm{CVC}$ are depicted in Figure 8. This figure shows that the strength after one day was not completely affected by the increase of the SP content in these mixes. Only the mix with $10 \%$ replacement showed a lower strength than the reference. The 7-day compressive strength, on the other hand, displayed an increase for all the substitution levels. The 28-day compressive strength showed similar trends as the 1-day compressive strength; only the mix with $10 \%$

Table 11. Mix designs of CVC with and without replacement of cement with olivine nano-silica

\begin{tabular}{ccccc}
\hline Materials $\left(\mathbf{k g} / \mathbf{m}^{\mathbf{3}}\right)$ & Reference & $\mathbf{5 \%}$ vol. & $\mathbf{7 \%}$ vol. & $\mathbf{1 0 \%}$ vol. \\
\hline Olivine NS & 0.0 & 6.9 & 10.3 & 13.7 \\
CEM I 52.5 N & 210 & 200 & 194 & 189 \\
Fly-Ash & 88.2 & 88.2 & 88.2 & 88.2 \\
Sand 0-4 & 781 & 781 & 781 & 781 \\
Gravel 4-16 & 1086 & 1086 & 1086 & 1086 \\
Water & 159 & 159 & 158 & 158 \\
SP (\% bwob) & 0.50 & 1.12 & 1.33 & 1.75 \\
w/f (\%) & 0.54 & 0.54 & 0.54 & 0.54 \\
Slump class & $\mathrm{S} 2$ & $\mathrm{~S} 2$ & $\mathrm{~S} 1$ & $\mathrm{~S} 1$ \\
Slump diam. (mm) & 60 & 60 & 40 & 40 \\
\hline
\end{tabular}

*Where f refers to fine materials below $125 \mu \mathrm{m}$.

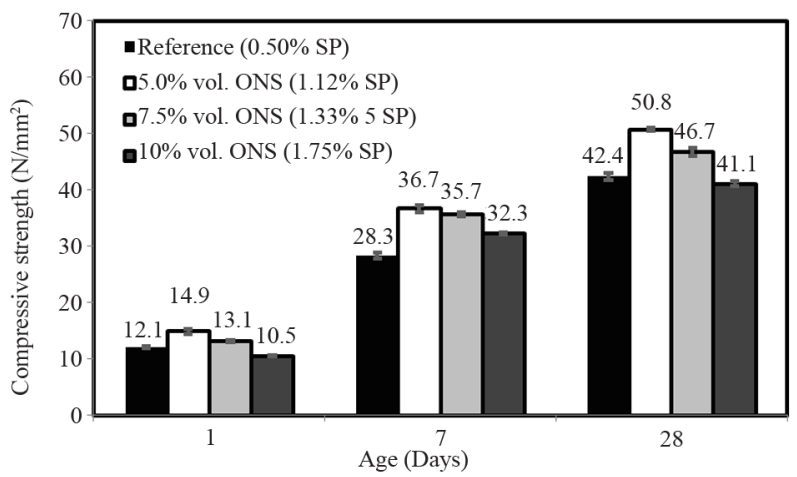

Figure 8. Compressive strength development of CVC at different replacement levels of cement with ONS. (ONS refer to olivine nano-silica). 
replacement showed a lower strength than the reference. The best result after 28 days was obtained for the mix with $5 \%$ replacement, where the compressive strength rose by $20 \%$ compared to the reference mix. This suggests that the optimum substitution of olivine nano-silica should be around this value.

Figure 9 presents the estimated $\mathrm{CO}_{2}$ footprint per cubic meter of reference $\mathrm{CVC}$ and $\mathrm{CVC}$ with $5 \%$ replacement. These estimations were performed using the $\mathrm{CO}_{2}$ footprint of each compound from a database of the Dutch precast concrete organization (VOBN). The $\mathrm{CO}_{2}$ footprint of olivine was estimated from a life cycle analysis performed by VTT (ProMine internal report, FP7). The reduction of $\mathrm{CO}_{2}$ emissions for $\mathrm{CVC}$ with $5 \%$ replacement was $3 \%$ with respect to the reference concrete. This could be improved by tailoring the properties of olivine nano-silica so less SP would be necessary to maintain the same rheological properties or slump class. Since the compressive strength of CVC with 5\% replacement was $20 \%$ higher than the reference concrete, there would be the possibility of reducing the total amount of concrete used while maintaining the same compressive strength as the reference material, therefore minimizing $\mathrm{CO}_{2}$ emissions.

\section{Conclusions}

Amorphous nano-silica can be produced by the dissolution of olivine, having a specific surface area between 100 and $400 \mathrm{~m}^{2} / \mathrm{g}$, a primary particle size between 10 and $25 \mathrm{~nm}$ (agglomerated in clusters) and a $\mathrm{SiO}_{2}$ content above $95 \%$. The $\mathrm{SiO}_{2}$ purity can be increased by employing additional cleaning steps to fulfill the sulfate requirements of the norm NEN - EN 13263-1 + A1. The olivine nano-silica process is: more sustainable because it requires less fuel (so fewer $\mathrm{CO}_{2}$ emissions), and it is possible to use waste materials as a silica source.
Waste dunite rocks with a low content of olivine can be beneficiated by dense media separation to produce a material with an olivine content of $75 \%$. The beneficiated material can be satisfactorily used for nano-silica production as long as the content of olivine is equal to or higher than $75 \%$, and the contents of carbonates, calcium and talc are low.

The compressive strength of the standard mortar is affected when cement is replaced with olivine nano-silica by $7 \%$ bwoc. This material can be classified as a pozzolanic material with activity indexes of $101 \%$. Further research is needed to obtain the optimum replacement level of cement for the olivine nano-silica.

Preliminary results demonstrated that the possible optimum replacement of olivine nano-silica in conventional vibrated concrete was around $5 \%$ with an improvement in the compressive strength of $20 \%$. The superplasticizer content has to be increased when cement is replaced with olivine nano-silica to maintain similar rheological properties. The $\mathrm{CO}_{2}$ emissions were reduced by $3 \%$ for the CVC with 5\% replacement compared to the reference concrete. The $\mathrm{CO}_{2}$ emissions could be further reduced if the SP content could be diminished by tailoring the properties of olivine nano-silica. Therefore, the use of the olivine nano-silica in CVC does not only improve its compressive strength but also reduce $\mathrm{CO}_{2}$ emissions. This green nano-silica can also be used in any other applications where the high specific surface area is required.

\section{Acknowledgements}

This research was carried out under the EU FP7 project ProMine: Nano-particle products from new mineral resources in Europe (grant agreement no 228559) and partially carried out under project number M81.1.09338 in the framework of the Research Program of the Materials
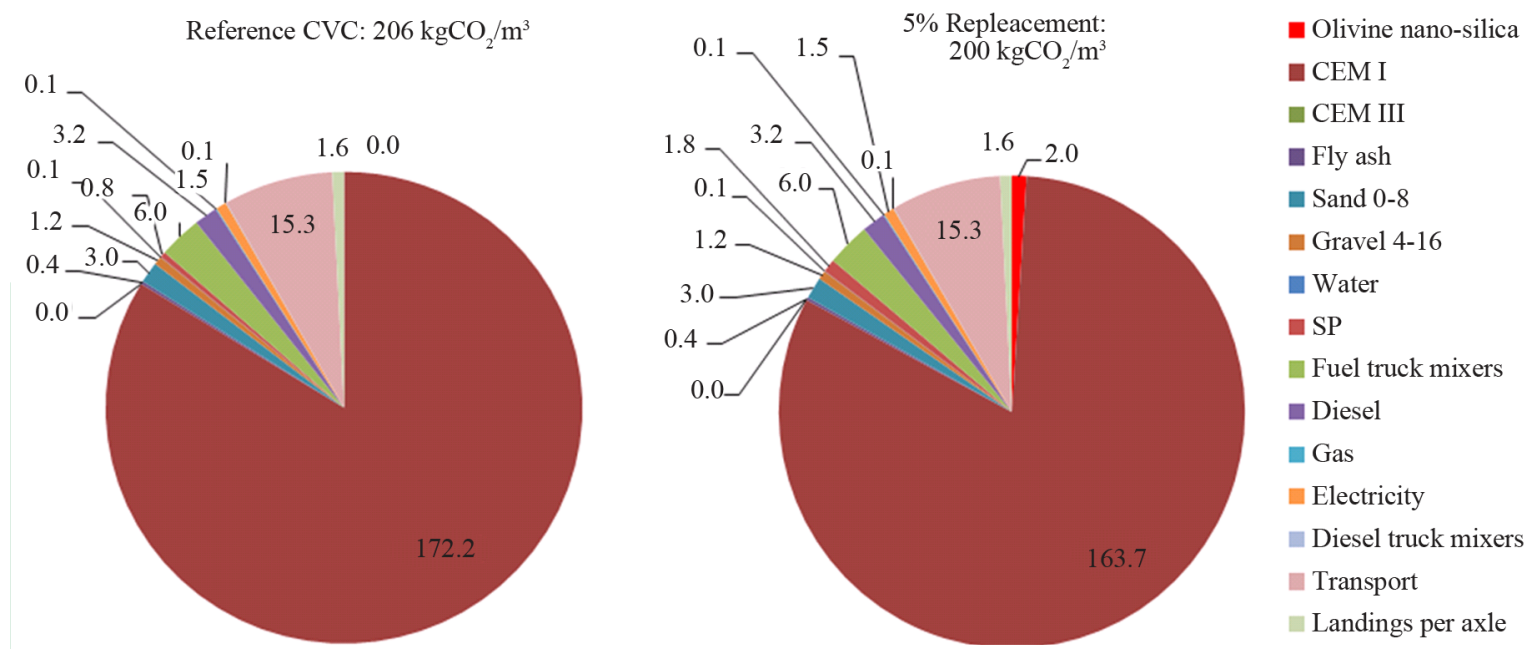

Figure 9. $\mathrm{CO}_{2}$ footprint of $\mathrm{CVC}$ and of $\mathrm{CVC}$ with $5 \%$ replacement of cement with ONS. 
innovation institute $\mathrm{M} 2 \mathrm{i}$ (www.m2i.nl). The authors wish to express their appreciations to Dr. J. H. Baker and J. Nokes for their fruitful discussions and comments, to Grecian Magnesite for the supply of the beneficiated material and to VTT for the determination of the $\mathrm{CO}_{2}$ footprint of olivine nano-silica. The authors also wish to express their gratitude to the following sponsors of the Building Materials research group at TU Eindhoven: Bouwdienst Rijkswaterstaat, Graniet-Import Benelux, Kijlstra Betonmortel, Struyk Verwo, Attero, Enci, Provincie Overijssel, Rijkswaterstaat Directie Zeeland, A\&G Maasvlakte, BTE, Alvon Bouwsystemen, V.d. Bosch Beton, Selor, Twee "R" Recycling, GMB, Schenk Concrete Consultancy, Intron, Geochem Research, Icopal, BN International, APP All Remove, Consensor, Eltomation, Knauf Gips, Hess ACC Systems and Kronos (chronological order of joining).

\section{REFERENCES}

[1] Report Linker, "World Specialty Silicas Market," 2010.

[2] M. Gribble, "Synthetic Amorphous Silica (CAS No. 763186-9)," Joint Assessment of Commodity Chemicals (JACC) Report No. 51, European Centre for Ecotoxicology and Toxicology of Chemicals, Brussels, 2006.

[3] G. E. Moore, "Combustion Process for Producing High Surface Area Silica,” US Patent No. 003772427, 1973.

[4] R. K. Iler, "The Chemistry of Silica: Solubility, Polymerization, Colloid and Surface Properties, and Biochemistry," John Wiley and Sons, New York, 1979.

[5] O. W. Flörke, H. A. Graetsch, F. Brunk, L. Benda, S. Paschen, H. E. Bergna, W. O. Roberts, W. A. Welsh, C. Libanati, M. Ettlinger, D. Kerner, M. Maier, W. Meon, R. Schmoll, H. Gies and D. Shiffmann, "Silica," Ullmann's Encyclopedia of Industrial Chemistry, Wiley, Online Library, 2008.

[6] A. M. Neville, "Properties of Concrete," Pearson Education Limited, Harlow, 1995.

[7] R. Siddique and M. I. Khan, "Supplementary Cementing Materials," Springer, Heidelberg, 2011.

[8] R. C. L. Jonckbloedt, "The Dissolution of Olivine in Acid, a Cost Effective Process for the Elimination of Waste Acids," PhD Thesis, Utrecht University, Utrecht, 1997.

[9] Cembureau, "World Cement Production by Region Evolution 2001-2011," Cembureau, Brussels, 2011.

[10] N. Vijayarethinam, "Silica Fume Applications," World Cement, Vol. 40, 2009, pp. 97-100.

[11] PBL, Netherlands Environmental Assessment Agency, "Trends in Global $\mathrm{CO}_{2}$ Emissions," 2012.

[12] O. S. Pokrovsky and J. Schott, "Kinetics and Mechanism of Forsterite Dissolution at $25^{\circ} \mathrm{C}$ and $\mathrm{pH}$ from 1 to 12 ," Geochimica et Cosmochimica Acta, Vol. 64, No. 19, 2000, pp. 3313-3325. doi:10.1016/S0016-7037(00)00434-8

[13] J. J. Rosso and J. D. Rimstidt, "A High Resolution Study of Forsterite Dissolution Rates," Geochimica et Cosmo- chimica Acta, Vol. 64, No. 5, 2000, pp. 797-811. doi:10.1016/S0016-7037(99)00354-3

[14] E. H. Oelkers, “An Experimental Study of Forsterite Dissolution Rates as a Function of Temperature and Aqueous Mg and Si Concentrations," Chemical Geology, Vol. 175, No. 3-4, 2001, pp. 485-494. doi:10.1016/S0009-2541(00)00352-1

[15] A. Lazaro, H. J. H. Brouwers, G. Quercia Bianchi and J. W. Geus, "The Properties of Amorphous Nano-Silica Synthesized by the Dissolution of Olivine," Chemical Engineering Journal, Vol. 211-212, 2012, pp. 112-121. doi:10.1016/j.cej.2012.09.042

[16] ISO, "Determination of the Specific Surface Area of Solids by Gas Adsorption-BET Method," 2010.

[17] H. E. Bergna and W. O. Roberts, "Colloidal Silica: Fundamentals and Applications," CRC, 2006.

[18] S. Brunauer, P. H. Emmett and E. Teller, "Adsorption of Gases in Multimolecular Layers," Journal of the American Chemical Society, Vol. 60, No. 2, 1938, pp. 309-319. doi: $10.1021 / \mathrm{ja} 01269 \mathrm{a} 023$

[19] J. H. de Boer, B. G. Linsen and T. Osinga, "Studies on Pore Systems in Catalysts: VI. The Universal t Curve," Journal of Catalysis, Vol. 4, No. 6, 1965, pp. 643-648. doi:10.1016/0021-9517(65)90263-0

[20] W. H. Harkins and G. Jura, "Surfaces of Solids. XIII. A Vapor Adsorption Method for the Determination of the Area of a Solid without the Assumption of a Molecular Area, and the Areas Occupied by Nitrogen and Other Molecules on the Surface of a Solid," Journal of the American Chemical Society, Vol. 66, No. 8, 1944, pp. 1366-1373.

[21] Micromeritics, "Tristar II 3020," Operator's Manual V1. 03, 2009.

[22] A. Lazaro, J. W. Geus and H. J. H.Brouwers, "Influence of the Production Process Conditions on the Specific Surface Area of Olivine Nano-Silicas," Proceedings of the International Conference Nanomaterials on Applications and Properties, Simferopol, 2012, pp. 1-4

[23] D. J. Lieftink, "The Preparation and Characterization of Silica from Acid Treatment of Olivine," $\mathrm{PhD}$ Thesis, Utrecht University, Utrecht, 1997.

[24] G. Quercia, A. Lazaro, J. W. Geus and H. J. H. Brouwers. "Characterization of Morphology and Texture of Several Amorphous Nano-Silica Particles Used in Concrete," Cement and Concrete Composites, 2013, in Press. doi:10.1016/j.cemconcomp.2013.05.006

[25] European Commission for Standardization, "CEN EN 196-1. Methods of Testing Cement Part 1: Determination of Strength," CEN, Brussels, 2005.

[26] H. Justnes and T. Ostnor, "Pozzolanic, Amorphous Silica Produced from the Mineral Olivine," Special Publication ACI, Vol. 199, 2001, pp. 769-782.

[27] J. Björnström, A. Martinelli, A. Matic, L. Börjesson and I. Panas, "Accelerating Effects of Colloidal Nano-Silica for Beneficial Calcium-Silicate-Hydrate Formation in Cement," Chemical Physics Letters, Vol. 392, No. 1-3, 2004, pp. 242-248. doi:10.1016/j.cplett.2004.05.071

[28] G. Land and D. Stephan, "The Influence of Nano-Silica 
on the Hydration of Ordinary Portland Cement," Journal of Materials Science, Vol. 47, No. 2, 2012, pp. 10111017.

[29] CEN, "European Committee for Standardization and Ne- derlands Normalisatie-Instituut. NEN-EN 13263-1+A1. Silica Fume for Concrete, Part 1: Definitions, Requirements and Conformity Criteria," CEN, Brussels, 2009. 